PO043

\title{
EFFECTS OF LIGHT COLOUR ON WORK EFFICIENCY AND ALERTNESS
}

\author{
HIROSHI TAKAHASHI et al.
}

DOI 10.25039/x46.2019.PO043

from

CIE x046:2019

\section{Proceedings}

of the

29th CIE SESSION

Washington D.C., USA, June 14 - 22, 2019

(DOI 10.25039/x46.2019)

The paper has been presented at the 29th CIE Session, Washington D.C., USA, June 14-22, 2019. It has not been peer-reviewed by CIE.

(C) CIE 2019

All rights reserved. Unless otherwise specified, no part of this publication may be reproduced or utilized in any form or by any means, electronic or mechanical, including photocopying and microfilm, without permission in writing from CIE Central Bureau at the address below. Any mention of organizations or products does not imply endorsement by the CIE.

This paper is made available open access for individual use. However, in all other cases all rights are reserved unless explicit permission is sought from and given by the CIE.

CIE Central Bureau

Babenbergerstrasse 9

A-1010 Vienna

Austria

Tel.: +4317143187

e-mail: ciecb@cie.co.at

www.cie.co.at 


\title{
EFFECTS OF LIGHT COLOUR ON WORK EFFICIENCY AND ALERTNESS
}

\author{
Takahashi, H., Watanabe, S. \\ Kanagawa Institute of Technology, Atsugi, JAPAN \\ htakahashi@ele.kanagawa-it.ac.jp
}

DOI 10.25039/x46.2019.PO043

\begin{abstract}
The use of light-emitting diode (LED) lighting has now become widespread. Such light sources emit light in the primary colours of red, green, and blue, and are thus capable of reproducing most chromatic colours. Such light colours have been found to have both physical and psychological effects on human beings. In this study aims to investigate how work efficiency and alertness can be affected by chromatic light. White, red, green, blue lights were used in this experiment. The subjects were asked to perform three different tasks and from the subjects electroencephalogram (EEG) data recorded throughout the experiments. As the results, it was suggested that the creative work may be influenced by light colour. Moreover, comparing white light and chromatic light, alertness was found to be higher in the chromatic light under all task period.
\end{abstract}

Keywords: Light Colour, Work Efficiency, Alertness, EEG

\section{Introduction}

The use of light-emitting diode (LED) lighting has now become widespread. Such light sources emit light in the primary colours of red, green, and blue, and are thus capable of reproducing most chromatic colours. Such light colours have been found to have both physical and psychological effects on human beings. For example, some studies[1],[2],[3] have reported that long-wavelength (red) light increases alertness in the daytime. Other studies[4],[5] have reported that chromatic colour lighting influences cognitive performance. However, the lighting conditions used in past studies are considered to be unnatural because they were conducted under low illuminance conditions, and those studies did not clarify the effects of chromatic colour lighting on alertness. Therefore, this study aims to investigate how work efficiency and alertness can be affected by chromatic light.

\section{Experiment}

Table 1 shows the experimental conditions. In this experiment, the work surface illuminance was set to $200 \mathrm{Ix}$. White, red, green, blue lights were used in this experiment. In this experiment, test subjects were asked to perform three different tasks: simple task 1 , simple task 2, idea task after adapting each lighting condition for 10 minutes. Simple task 1 was calculation task. Calculation task was hundred-square calculations. Hundred-square calculations involve a 10-by-10 grid, which is filled in by adding the numbers at the top and side of the grid. Simple task 2 was typing task. Typing task was typing Japanese sentences. Idea task was matchstick puzzle.

From the subjects electroencephalogram (EEG) data recorded throughout the experiments. Electrodes were placed on subject's scalps according to the International 10-20 system at C3 and C4. An additional electrode was attached at A1 to serve as reference electrode for those attached to the scalp. Data were grouped into the following two frequency ranges: $8-12.5 \mathrm{~Hz}$ (alpha), $13-30 \mathrm{~Hz}$ (beta). The ratio beta/alpha was used as an index of alertness level in this study. In each frequency range, the EEG power at each interval was normalized to the power obtained during the initial light colour adaptation.

The following procedure was used in this experiment: 
(1) The subjects were given 10 minutes to adapt to the chromatic lighting of the experimental environment and EEG data was recorded during this adaptation period.

(2) The subjects performed simple task 1 and EEG data was recorded during this period.

(3) The subjects performed simple task 2 and EEG data was recorded during this period.

(4) The subjects performed idea task and EEG data was recorded during this period.

Steps (1) to (4) were repeated for each light colour, which were selected at random to avoid an order effect.

Table 1 - Experimental conditions

\begin{tabular}{|c|c|}
\hline Light source & LED \\
\hline Work space illuminance & $200 \mathrm{Ix}$ \\
\hline Light source height & $0.8 \mathrm{~m}$ \\
\hline \multirow{2}{*}{ Chromaticity } & White: $(0.28,0.25)$ \\
& Red: $(0.70,0.30)$ \\
& Green: $(0.20,0.72)$ \\
& Blue: $(0.13,0.07)$ \\
\hline Subjects & 7 males in their $20 \mathrm{~s}$ \\
\hline
\end{tabular}

\section{Results and Discussion}

A one-factor analysis of variance (ANOVA) was performed in this study. The factor was light colour and multiple comparisons were performed using Fisher's least significant difference (LSD) method. Figure 1 shows the work efficiency of each task. The work efficiency at each light colour was normalized to the work efficiency at white light. Here, the work efficiency of the idea task shows the correct answer rate.

In the simple task 1, work efficiency at red light was hardly changed, and at green light was slightly increased. The work efficiency at blue light was decreased. In the simple task 2 , work efficiency at red light was slightly decreased, and at green light was slightly increased. The work efficiency at blue light was decreased. In the idea task, work efficiency at red light was increased drastically and at green light was increased. The work efficiency at blue light was decreased. However no significant difference was observed in each task for each light colour.

Figure 2 shows the alertness of each period. Comparing white light and chromatic light, alertness was found to be higher in the chromatic light under all task period. In the simple task 1 and 2, the alertness was higher in order of blue light, green light and red light. In the idea task, the alertness was higher in order of blue light, red light and green light. However no significant difference was observed in each task for each light colour.

Figure 3 shows the relationship between work efficiency and alertness. In the all task case, work efficiency at blue light with highest alertness was decreased. This is suggested that blue light is not suitable for working environment. The work efficiencies and alertness were increased under green light in the all task. This is suggested that green light is suitable for working environment.

It was clarified that there was no correlation between work efficiency and alertness of simple tasks in this experiment. On the other hand, the work involving creativity such as the idea task may be influenced by light colour.

A more detailed investigation will need to be undertaken in the future in order to confirm these initial findings. 


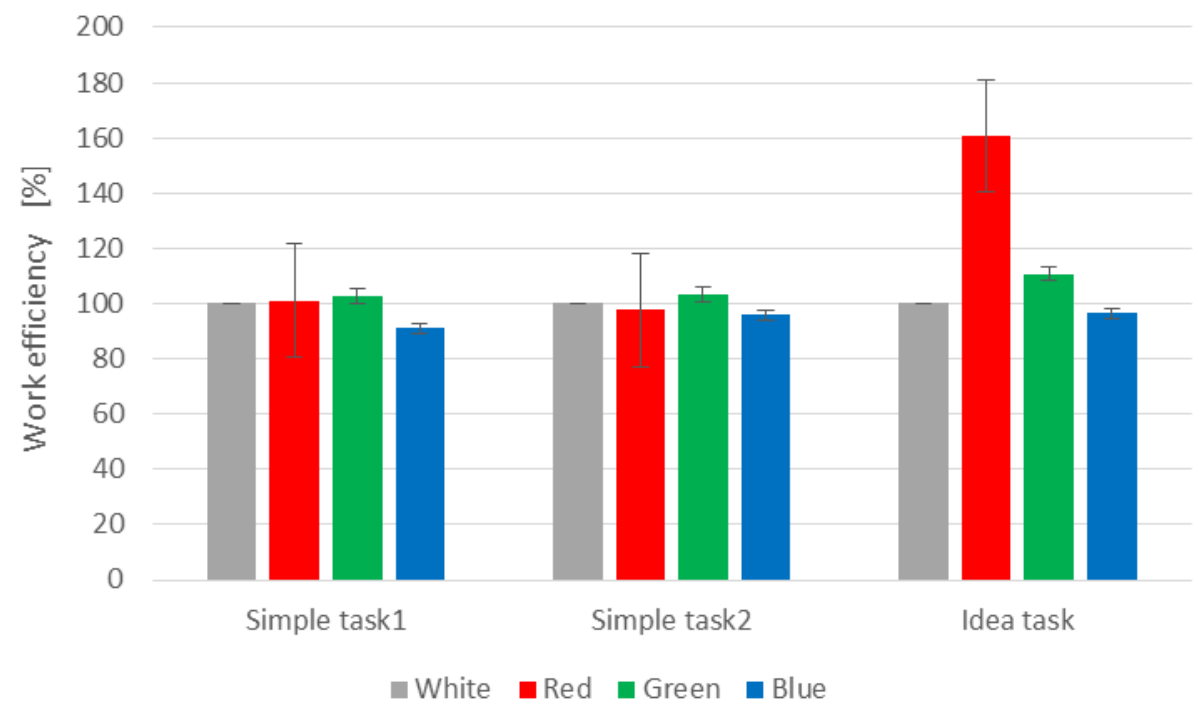

Figure 1 - Work efficiency of each task

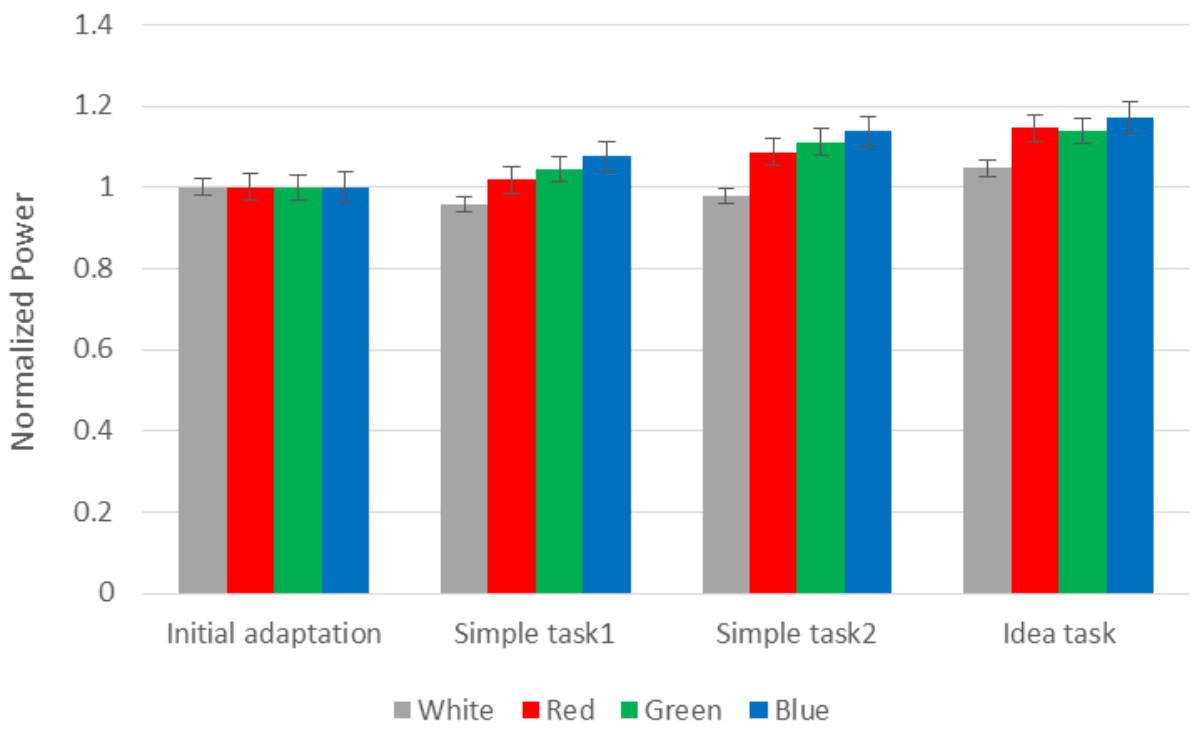

Figure 2 - Alertness of each period 


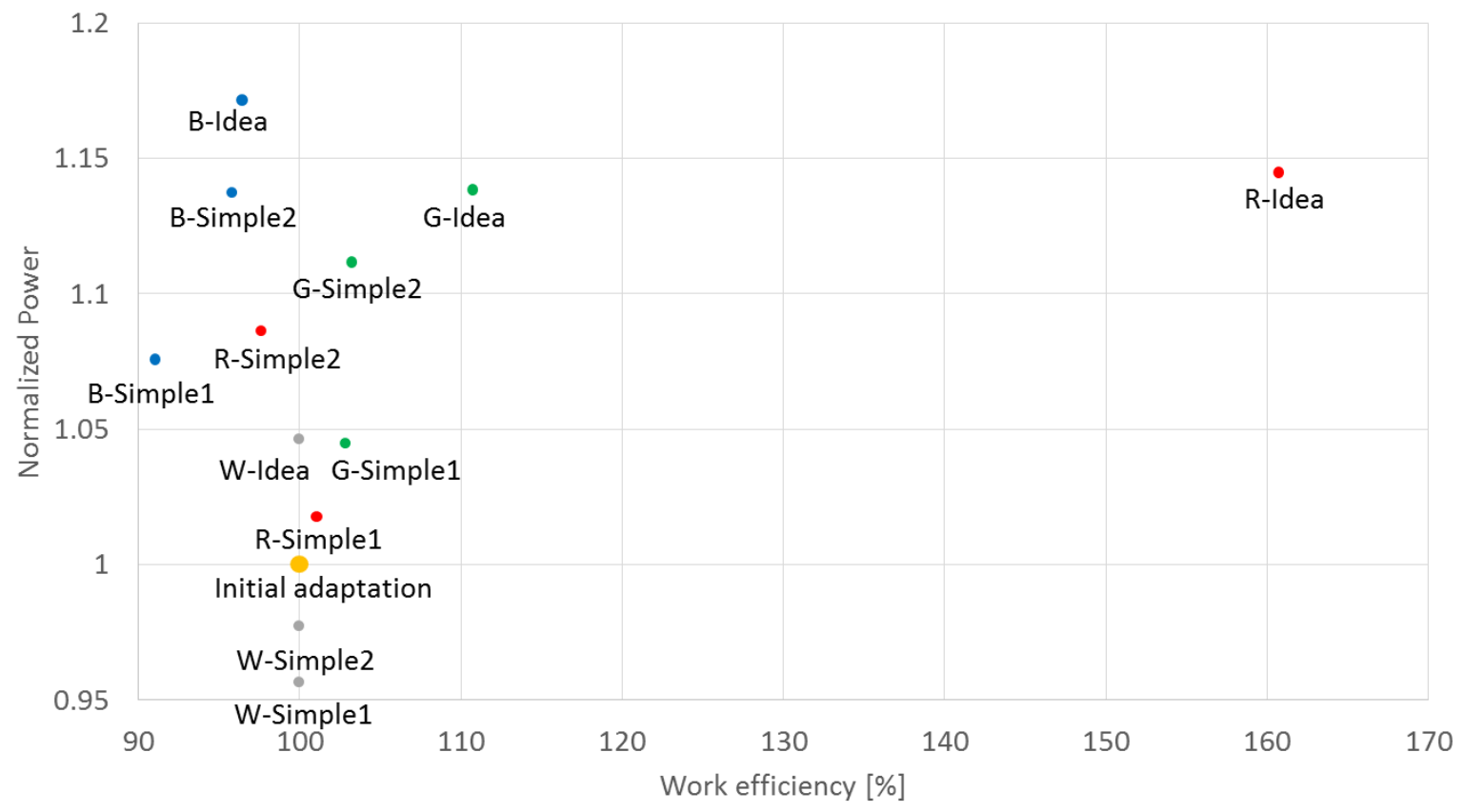

Figure 3 - Relationship between work efficiency and alertness

\section{Conclusion}

In this study, we conducted the experiment to clarify the influence of light colour on work efficiency and alertness. The results can be summarized as follows:

(1) It is suggested that the creative work may be influenced by light colour.

(2) Green light is suitable for working environment in this study.

This study was approved by the Ethical Review Board for the use of human subjects of Kanagawa Institute of Technology (No. 20180322-20).

\section{References}

[1] PLITNICK, B., FIGUEIRO, MG., WOOD, B. \& REA, MS. 2010. The effects of red and blue light on alertness and mood at night. Lighting Research and Technology, 42(4), 449-458.

[2] SAHIN, L. \& FIGUEIRO, MG. 2013. Alerting effects of short-wavelength (blue) and longwavelength (red) lights in the afternoon. Physiology \& Behavior, 116-117, 1-7.

[3] SAHIN, L., WOOD, BM., PLITNICK, B., FIGUEIRO, MG. 2014. Daytime light exposure: Effects on biomarkers, measures of alertness, and performance. Behavioural Brain Research, 274, 176-185.

[4] KOJIMA, H. and MIURA, H. 2012. Examining the Effect of Illumination Color on Cognitive Performance, J. Illum. Engng.Inst. Jpn., 96( 2), 95-99.

[5] TAKAHASHI, H., UETSUHARA, T., KOHAMA, S. 2016. Effects of chromatic colour lighting on work efficiency. PROCEEDINGS of the 4th CIE Expert Symposium on Colour and Visual Appearance, 476-479. 